\title{
Control of Benzimidazole- and DMI-Resistant Strains of Cercospora beticola with Strobilurin Fungicides
}

\author{
G. S. Karaoglanidis, Hellenic Sugar Industry S.A., Plant Protection Department, Sugar Factory of Platy, 59032, \\ Platy Imathias, Greece; and G. Bardas, Aristotelian University of Thessaloniki, Faculty of Agriculture, Plant Pa- \\ thology Laboratory, POB 269, 54006, Thessaloniki, Greece
}

\begin{abstract}
Karaoglanidis, G. S., and Bardas, G. 2006. Control of benzimidazole- and DMI-resistant strains of Cercospora beticola with strobilurin fungicides. Plant Dis. 90:419-424.

The control efficacy of two new strobilurin fungicides, trifloxystrobin and pyraclostrobin, against Cercospora beticola isolates resistant and sensitive to sterol demethylation-inhibiting (DMI) fungicides and benzimidazole fungicides and the effects on evolution of resistance were tested in the current study. Control efficacy of strobilurin fungicides was measured using three C. beticola isolates, one DMI-resistant (DMIR), one benzimidazole-resistant (BENR), and one of wild-type sensitivity (WCB). Both pyraclostrobin and trifloxystrobin provided satisfactory control of all the three isolates used in the study, when applied at $5 \mu \mathrm{g} \mathrm{ml}^{-1}$ and very high levels of control when applied at $10 \mu \mathrm{g} \mathrm{ml}^{-1}$. Control was independent of the isolate sensitivity to benomyl and difenoconazole. In contrast, benomyl applied at $10 \mu \mathrm{g} \mathrm{m}^{-1}$ failed to control sufficiently the benzimidazole-resistant isolate, whereas difenoconazole applied at either 5 or $10 \mu \mathrm{g}$ $\mathrm{ml}^{-1}$ failed to provide satisfactory control of the DMI-resistant isolate of the pathogen. The effects of strobilurin fungicide applications on the evolution of resistance to benzimidazole and DMI fungicides were tested under field conditions in a 2-year experiment (2003 to 2004). Applications of either trifloxystrobin or pyraclostrobin provided high levels of disease control during both years of the study, whereas applications of either benomyl or difenoconazole provided a moderate control efficacy. Measurements of resistance frequencies to benomyl and to difenoconazole showed that successive applications of benomyl tended to select for high frequencies of benzimidazole-resistant phenotypes, whereas successive applications of difenoconazole tended to select for high frequencies of DMI-resistant phenotypes. In contrast, applications of either trifloxystrobin or pyraclostrobin prevented an increase of benzimidazole- or DMI-resistant phenotypes compared with the plots treated with benomyl or difenoconazole, respectively, and decreased frequency of resistance compared with untreated control plots.
\end{abstract}

Additional keywords: Cercospora leaf spot, sugar beet, trifloxystrobin

Sugar beet leaf spot, caused by Cercospora beticola, is the most important foliar disease of sugar beet in warm and humid areas such as parts of the Mediterranean basin (5). In the absence of control measures, in areas with high disease incidence, yield losses range from 25 to $50 \%(5,35)$. Cercospora leaf spot is controlled primarily by fungicides, because nonchemical alternatives do not provide commercially acceptable control. Fungicides of several classes are available for use against the disease worldwide (30). Protectant fungicides used against the disease belong to the dithiocarbamate class, such as maneb and mancozeb, the nitrile class, such as chlorothalonil, and the class of organotin compounds, such as fentin-acetate and fentin-hydroxide. Systemic fungicides

Corresponding author: G. S. Karaoglanidis

E-mail: gkarao@agro.auth.gr

Accepted for publication 19 October 2005

DOI: 10.1094/PD-90-0419

(C) 2006 The American Phytopathological Society used against the disease belong to the benzimidazole class, such as benomyl and carbendazim, and the sterol demethylationinhibiting (DMI) class, such as flutriafol, difenoconazole, tetraconazole, and propiconazole. However, development of resistance to some of these fungicide classes, both in Greece and in many other countries worldwide, has become a limitation to the sustained control of the disease by restricting the initial utility of these fungicides.

The benzimidazole derivatives were the first systemic fungicides that became available for $C$. beticola control. In Greece, applications of benomyl began in 1971 with excellent results; however, within 2 years, the fungal populations developed resistance and fungicide efficacy was completely lost (11). Similarly, development of resistance and loss of fungicide efficacy also have been reported in several other countries $(9,31,34,40)$. In Greece, after the emergence of benzimidazole resistance, the use of benomyl was discontinued. However, in 1995, it was found that resistance frequency to benomyl had greatly decreased since 1972. Since then, benomyl had been reintroduced into the spray program, in one application early in the season, in some areas of Greece. However, sensitivity monitoring programs showed that even one spray application of benomyl had, as a consequence, a rapid selection of resistant strains (19).

DMI fungicides have been used in Greece for the control of this disease since 1979. These fungicides always are used in a mixture with a protectant fungicide, either maneb or chlorothalonil. However, after 1990, a reduction in the performance of DMI fungicides was observed in northern Greece and an extensive monitoring program showed that fungal populations had shifted toward decreased sensitivity $(16,18)$

Strobilurin fungicides constitute a relatively new fungicide class that has been developed from natural fungicidal derivatives such as strobilurin A, oudemansin A, and myxothiazol A (4). This fungicide class possesses a new mechanism of action consisting of inhibition of mitochondrial respiration by binding at the $\mathrm{Q}_{0}$ site of cytochrome $b$. Inhibition of mitochondrial respiration is achieved by blocking the electron transport between cytochrome $b$ and cytochrome $c_{1}$ which, in consequence, leads to a disruption of the energy cycle $(3,4)$. This fungicide class possesses an extremely broad spectrum of activity, including several fungal classes, such as Ascomycetes, Deuteromycetes, and Basidiomycetes, and other organisms, such as Oomycetes $(1,28,42,44)$. Among the several pathogens that are efficiently controlled by strobilurin fungicides, $C$. beticola also is included, as has been shown by recent studies under both controlled environmental conditions $(2,15)$ and field conditions (21).

The current study was conducted to (i) test the efficacy of the strobilurin fungicides trifloxystrobin and pyraclostrobin in controlling benzimidazole- and DMIresistant strains of $C$. beticola under in planta conditions and (ii) determine the effects of trifloxystrobin and pyraclostrobin applications on the evolution of resistance to benzimidazole and DMI fungicides under field conditions.

\section{MATERIALS AND METHODS}

In planta experiments. Fungi. Three $C$. beticola isolates, one benzimidazoleresistant (BENR), one DMI-resistant (DMIR), and one of wild-type sensitivity 
(WCB), were used in the study. All the isolates were obtained from single lesions, collected from sugar beet fields in October 2003 during a routine sensitivity monitoring of $C$. beticola field isolates to several fungicides. Pure cultures were obtained by single-spore isolation using the dilution technique (38). The sensitivity to difenoconazole and benomyl of each purified culture was retested as for the single-lesion isolates. Measurement of sensitivity to difenoconazole and to benomyl was based on the inhibition of mycelial growth, whereas measurement of sensitivity to trifloxystrobin and pyraclostrobin was based on the inhibition of spore germination. Isolations and sensitivity determinations were carried out on Aspergillus complete medium (ACM) composed of $20 \mathrm{~g}$ of agar (Oxoid; Unipath Ltd., Basingstoke, England), $10 \mathrm{~g}$ of dextrose (Merck, Darmstadt, Germany), and $1 \mathrm{~g}$ of yeast extract (Oxoid) per liter. The methodology of isolation and sensitivity determination has been described previously $(15,16,20)$. Measurements of mycelial growth inhibition for each isolate, to determine the sensitivity to difenoconazole and benomyl, were replicated four times per concentration of each fungicide tested. For the measurement of strobilurin sensitivity, 100 conidia were counted per isolate with three replicate measurements for each fungicide concentration tested. Details on the sensitivity to these fungicides of isolates are given (Table 1).

Plant material. All the in planta experiments were conducted on Beta vulgaris L. cv. Europa plants, a cultivar which is very susceptible to Cercospora leaf spot. Plants were grown in the greenhouse $\left(18\right.$ to $\left.26^{\circ} \mathrm{C}\right)$ in plastic pots (18 cm in diameter) containing a 2:1 (vol:vol) mixture of peat and perlite. Plants were fertilized once per week with $1 \%$ N-P-K (20:20:20) solution. Each pot contained two plants. Plants used for inoculations were 7 to 8 weeks old, at the stage of six to eight fully expanded leaves.

Fungicides. Fungicides used in the study were commercial formulations of trifloxystrobin (Flint $50 \mathrm{WG}$, Bayer Hellas, Athens), pyraclostrobin (F-500 25 EC, BASF Hellas, Athens), benomyl (Benlate 50WP, DuPont Agro Hellas, Athens) and difenoconazole (Score 25 EC, Syngenta Hellas,
Athens). The fungicides were applied to runoff with a hand sprayer $24 \mathrm{~h}$ before the inoculation of plants. Trifloxystrobin, pyraclostrobin, and difenoconazole were applied at 5 and $10 \mu \mathrm{g}$ a.i. $\mathrm{ml}^{-1}$, whereas benomyl was applied at $10 \mu \mathrm{g}$ a.i. $\mathrm{ml}^{-1}$. In addition, plants were treated with mixtures of trifloxystrobin or pyraclostrobin both applied at $5 \mu \mathrm{g}$ a.i. $\mathrm{ml}^{-1}$ and difenoconazole or benomyl both applied at $10 \mu \mathrm{g}$ a.i. $\mathrm{ml}^{-1}$. Control plants were sprayed with sterile tap water.

Artificial inoculations. For production of C. beticola inoculum, the three isolates tested were cultured on V8 juice agar medium (38). After 10 days of incubation under fluorescent light at $25^{\circ} \mathrm{C}$, sporulating colonies were rinsed with $15 \mathrm{ml}$ of distilled water and the conidial suspension was filtered through a double-layered sterile cheesecloth. Plants were artificially inoculated with conidial suspensions containing $20 \times 10^{4}$ conidia/ml. Before inoculation, one droplet of Tween 20 of $0.1 \%$ ( $\mathrm{vol} / \mathrm{vol})$ initial concentration was added to each suspension. The inoculation was carried out with a spray atomizer and plants were sprayed until runoff on both leaf surfaces. Plants were transferred to the growth chamber and kept at $27^{\circ} \mathrm{C}$ and $99 \%$ relative humidity, with a $16-\mathrm{h}$ photoperiod.

Disease assessment. When new lesions were no longer produced (about 20 days after inoculation), the plants were removed from the growth chamber and the disease severity on four fully expanded leaves per plant was recorded according to the ninecategory scale disease index of Kleinwanzlebener Saatzucht (KWS), where $1=$ healthy leaf and $9=$ leaf and leaf stalk dead and dried up (35). This scale was adopted because it was suitable for scoring the disease severity on individual leaves.

Field experiments. Experimental design. Field trials were conducted in the region of Imathia, northern Greece, during a 2-year period from 2003 to 2004. The experiments were established in a different field each year. In this area, disease incidence is rather high and six to seven fungicide spray applications per growing season are required for satisfactory disease control. Sensitivity monitoring programs carried out yearly since the early 1990 s had shown that phenotypes resistant to both to benzimidazole and DMI fungicides exist in

Table 1. Level of sensitivity (in terms of $\mathrm{EC}_{50}$ values) of the Cercospora beticola isolates used in in planta experiments

\begin{tabular}{lcccc}
\hline & \multicolumn{4}{c}{$\mathbf{E C}_{\mathbf{5 0}}\left(\boldsymbol{\mu g} \mathbf{~ m l}^{-\mathbf{1}}\right)^{\mathbf{y}}$} \\
\cline { 2 - 5 } Isolates $^{\mathbf{z}}$ & Difenoconazole & Benomyl & Trifloxystrobin & Pyraclostrobin \\
\hline BENR & 0.015 & $>100$ & 0.0015 & 0.0020 \\
DMIR & 0.780 & 0.05 & 0.0031 & 0.0030 \\
WCB & 0.012 & 0.04 & 0.0011 & 0.0025 \\
\hline
\end{tabular}

${ }^{y}$ Measurement of effective concentration that reduces the mycelial growth or spore germination by $50 \%\left(\mathrm{EC}_{50}\right)$ values was based on mycelial growth test for difenoconazole and benomyl and on spore germination test for trifloxystrobin and pyraclostrobin.

${ }^{\mathrm{z}} \mathrm{BENR}=$ benzimidazole-resistant isolate, DMIR = sterol demethylation-inhibiting-resistant isolate, and $\mathrm{WCB}=$ wild-type sensitivity isolate this area, in relatively high frequencies $(18,20)$.

The sugar beet cultivar selected for the experiment was Rival, a cultivar susceptible to the Cercospora leaf spot disease. In order to minimize, as much as possible, the risk of interplot interference, the plots were separated from each other by a 4-m buffer zone kept free of sugar beet plants. Experimental field plots were of 6 by $12 \mathrm{~m}$ in size, including 12 sugar beet rows, and arranged in a randomized block design.

The experiment consisted of five different spray treatments with four replicate plots per treatment. The treatments used were (i) control, untreated; (ii) trifloxystrobin applied at $200 \mathrm{~g}$ a.i. $\mathrm{ha}^{-1}$; (iii) pyraclostrobin applied at $200 \mathrm{~g}$ a.i. $\mathrm{ha}^{-1}$; (iv) difenoconazole applied at $150 \mathrm{~g}$ a.i. $\mathrm{ha}^{-1}$; and (v) benomyl applied at $250 \mathrm{~g}$ a.i. $\mathrm{ha}^{-1}$.

Fungicides were applied preventively. Spray applications were initiated before the appearance of any disease symptom on the plants, just after the "closing" of the rows, and were repeated at intervals of 15 to 18 days. In total, six spray applications per treatment were carried out. Fungicide solutions were applied using an AZO precision sprayer, at a volume of 0.4 liters/plot and pressure $4 \mathrm{~atm}$.

Disease development was assessed visually, by using the 12-degree rating scale of Horsfall and Barrat (12). Assessments of the disease began just after the appearance of symptoms and were repeated in 10- to 15-day intervals until the end of the experiment. Area under the disease progress curve (AUDPC) was calculated for the assessment period as follows (41):

$$
\text { AUDPC }=\sum_{i=1}^{n}\left[\left(Y_{i+1}+Y_{i}\right) / 2\right]\left(t_{i+1}-t_{i}\right)
$$

where $Y_{i}=$ disease severity at the $i$ th observation, $t_{i}=$ time (days) at the $i$ th observation, and $n=$ total number of observations.

Samplings and pathogen isolations. The first sampling was carried out just after the appearance of the first disease symptoms on sugar beet leaves in the control treatments, in order to measure the pretreatment sensitivity of $C$. beticola population within the experimental field. The second sampling was carried out about 20 days after the sixth spray application. In the second sampling, fungal isolates were obtained from all the plots of all the treatments. In all, 15 leaves were sampled from each experimental plot and a total of 60 leaves per treatment were obtained. Only plants within the two central rows of each plot were selected, and only one leaf with distinct sporulating lesions was cut off randomly from each plant. The leaves were transferred into the laboratory to isolate the pathogen according to a procedure described previously (16). Only one isolate was obtained from each selected leaf and, in total, 60 isolates were obtained per treatment. 
Determination of resistance frequency to difenoconazole and benomyl. Autoclaved ACM was cooled to $50^{\circ} \mathrm{C}$ and amended with aqueous fungicide solutions at discriminatory concentrations of difenoconazole and benomyl to determine the resistance frequencies. The discriminatory concentration for benomyl was $1 \mu \mathrm{g} \mathrm{ml}^{-1}$, a concentration completely inhibitory for the sensitive isolates but not for the resistant isolates $(11,20)$. To determine the resistance frequency to difenoconazole, $0.1 \mu \mathrm{g}$ $\mathrm{ml}^{-1}$ was used as a discriminatory concentration, which was completely inhibitory for the difenoconazole-sensitive strains of the pathogen while allowing the growth of resistant isolates (19). The discrimination between sensitive and resistant isolates was carried out after 5 days of incubation at $25^{\circ} \mathrm{C}$ in the dark. Tests for each isolate were replicated twice per concentration of each fungicide.

Data analysis. To compare disease severity in in planta experiments, an analysis of variance was conducted using the Fisher's least significant difference (LSD) test. Because data from the two replications did not differ significantly $(P>0.05)$, the mean disease severity values from the two experiments for each isolate and treatment were used in the data analysis. Values of AUDPC also were subjected to an analysis of variance and compared by Fisher's LSD test. Mean percentage values of resistance frequencies were compared with the Duncan multiple range test at $P=$ 0.05 . Prior the statistical analysis, percentage values were transformed to arcsine $\sqrt{\%}$. The statistical analysis was supported by Mstat-C statistical program (Mstat-C, version 2.10; Michigan State University, East Lansing).

\section{RESULTS}

Fungicide efficacy in in planta experiments. Applications of both pyraclostrobin and trifloxystrobin at the highest concentration tested $\left(10 \mu \mathrm{g} \mathrm{ml}^{-1}\right)$ provided excellent control of all three isolates on the inoculated plants. Applications at the lower rate of $5 \mu \mathrm{g} \mathrm{ml}^{-1}$ were intermediate in efficacy $(P<0.05)$. Conversely, applications of difenoconazole alone were not effective in controlling the DMIR isolate at either application tested, while providing satisfactory control of the BENR and WCB isolates. Similarly, applications of benomyl at $10 \mu \mathrm{g} \mathrm{ml}^{-1}$ failed to protect plants inoculated with the BENR isolate, whereas it was equally effective $(P>0.05)$ compared with strobilurin fungicides applied at $10 \mu \mathrm{g}$ $\mathrm{ml}^{-1}$ in controlling the DMIR and WCB isolates. The mixtures of the strobilurin fungicides tested with either difenoconazole or benomyl were highly effective against the disease, independently of the isolate used for the inoculations. Disease severity in all the fungicide treatments tested was significantly $(P<0.05)$ lower than the respective control treatments.
Data on the disease severity are summarized in Table 2 .

Fungicide efficacy in field experiments. A heavy Cercospora leaf spot attack developed during both years of the study in the fields selected for the experiment. During 2003, climatic conditions were more favorable for disease development and disease severity was higher compared with that in 2004. Data on disease severity, in terms of AUDPC values, on sugar beet plants in plots treated with the several fungicide spray schedules and control efficacy of these treatments throughout the 2-year period are shown in Table 3.

In plots treated with either trifloxystrobin or pyraclostrobin, disease severity, in terms of AUDPC values, was significantly lower $(P>0.05)$ than for all the other treatments during both years of the study, providing high control efficacy that ranged from 88.7 to $93.3 \%$. Disease severity in plots treated with difenoconazole was higher $(P<0.05)$ than that in plots treated with strobilurin fungicides but lower $(P<0.05)$ than that in benomyltreated plots, with control efficacy values of 76.5 and $77.4 \%$ during 2003 and 2004, respectively. Applications of benomyl were the least effective compared with the remaining fungicide treatments, with control efficacy values of 64.7 and $63.3 \%$ during
2003 and 2004, respectively. However, it should be mentioned that, in this treatment, disease severity was not significantly different from the respective values of the other fungicide treatments during the first stages of disease development during both years of the study.

Resistance frequency to difenoconazole and benomyl. In control plots, resistance frequencies of fungal population to difenoconazole and benomyl were determined twice per year. The first determination was carried out in isolates obtained from the first lesions that appeared during early summer (pretreatment determination), whereas the second determination of resistance frequency was carried out after the end of the spraying period (posttreatment determination). Resistance frequency, in isolates obtained from the fungicide-treated plots was determined once per year after the end of the fungicide spray applications. In control plots, resistance frequency remained unchanged during both years of the study. Resistance frequency to difenoconazole in the pretreatment measurement had values of 13.3 and $10 \%$ in 2003 and 2004, respectively; whereas, at the end of the spraying period, the respective values were 15.0 and $11.6 \%$ (Fig. 1). Similarly, pretreatment resistance frequency to benomyl in control plots had

Table 2. Cercospora leaf-spot severity ${ }^{\mathrm{x}}$ on sugar beet plants inoculated with Cercospora beticola isolates and treated with various fungicides

\begin{tabular}{lcccc}
\hline & & & Isolate $^{\mathbf{y}}$ & \\
\cline { 3 - 5 } Fungicide treatment & Dose $^{\mathbf{z}}$ & BENR & DMIR & WCB \\
\hline Benomyl & 10 & $4.52 \mathrm{~b}$ & $1.00 \mathrm{~d}$ & $1.00 \mathrm{c}$ \\
Difenoconazole & 5 & $2.36 \mathrm{c}$ & $4.56 \mathrm{~b}$ & $2.33 \mathrm{~b}$ \\
Difenoconazole & 10 & $1.00 \mathrm{~d}$ & $2.77 \mathrm{c}$ & $1.00 \mathrm{c}$ \\
Trifloxystrobin & 5 & $2.22 \mathrm{c}$ & $2.18 \mathrm{~d}$ & $2.00 \mathrm{c}$ \\
Trifloxystrobin & 10 & $1.00 \mathrm{~d}$ & $1.00 \mathrm{~d}$ & $1.00 \mathrm{c}$ \\
Pyraclostrobin & 5 & $2.95 \mathrm{c}$ & $3.00 \mathrm{c}$ & $2.82 \mathrm{~b}$ \\
Pyraclostrobin & 10 & $1.00 \mathrm{~d}$ & $1.00 \mathrm{~d}$ & $1.00 \mathrm{c}$ \\
Trifloxystrobin + difenoconazole & $5+10$ & $1.00 \mathrm{~d}$ & $1.00 \mathrm{~d}$ & $1.00 \mathrm{c}$ \\
Trifloxystrobin + benomyl & $5+10$ & $1.00 \mathrm{~d}$ & $1.00 \mathrm{~d}$ & $1.00 \mathrm{c}$ \\
Pyraclostrobin + difenoconazole & $5+10$ & $1.00 \mathrm{~d}$ & $1.10 \mathrm{~d}$ & $1.00 \mathrm{c}$ \\
Pyraclostrobin + benomyl & $5+10$ & $1.25 \mathrm{~d}$ & $1.00 \mathrm{~d}$ & $1.00 \mathrm{c}$ \\
Control & $\ldots$ & $4.88 \mathrm{a}$ & $5.11 \mathrm{a}$ & $4.98 \mathrm{a}$ \\
\hline
\end{tabular}

${ }^{x}$ Measurements based on the nine-category scale disease index of Kleinwanzlebener Saatzucht (35).

y $\mathrm{BENR}$ = benzimidazole-resistant isolate, DMIR = sterol demethylation-inhibiting-resistant isolate, and WCB = wild-type sensitivity isolate. Means followed by different letters in the column are significantly different according to Fischer's least significant difference test at $P=0.05$.

${ }^{\mathrm{z}}$ Application dose $\left(\mu \mathrm{g} \mathrm{ml^{-1 }}\right.$ a.i. $)$

Table 3. Area under the disease progress curve (AUDPC) values of Cercospora leaf-spot and control efficacy (Control) in experimental field plots treated with various fungicides ${ }^{\mathrm{y}}$

\begin{tabular}{lcrcrcc}
\hline & & \multicolumn{2}{c}{$\mathbf{2 0 0 3}$} & & \multicolumn{2}{c}{$\mathbf{2 0 0 4}$} \\
\cline { 3 - 4 } \cline { 6 - 7 } Treatment & Dose $^{\mathbf{n}}$ & AUDPC & Control (\%) & & AUDPC & Control (\%) \\
\hline Benomyl & 250 & $1.652 \mathrm{~b}$ & 64.7 & & $1.230 \mathrm{~b}$ & 63.3 \\
Difenoconazole & 150 & $1.100 \mathrm{c}$ & 76.5 & & $758 \mathrm{c}$ & 77.4 \\
Trifloxystrobin & 200 & $316 \mathrm{~d}$ & 93.3 & & $226 \mathrm{e}$ & 93.3 \\
Pyraclostrobin & 200 & $332 \mathrm{~d}$ & 92.9 & & $381 \mathrm{~d}$ & 88.7 \\
Control & $\ldots$ & $4.671 \mathrm{a}$ & 0.00 & & $3.350 \mathrm{a}$ & 0.00 \\
\hline
\end{tabular}

y AUDPC values were calculated according to Wolf and Verreet (41). Means followed by different letters in the column are significantly different according to Fischer's least significant difference test at $P=0.05$.

z Application dose (g a.i. ha $\left.{ }^{-1}\right)$. 
values of 16.6 and $13.3 \%$ in 2003 and 2004, respectively and remained stable throughout the spraying period, with values of 15 and $13.3 \%$ in 2003 and 2004, respectively (Fig. 2).

Resistance frequency to difenoconazole in difenoconazole-treated plots was significantly higher $(P<0.05)$ compared with that in the untreated control plots or plots treated with benomyl or strobilurin fungicides with values of 28.3 and $23.3 \%$ in 2003 and 2004, respectively (Fig. 1). In contrast, in strobilurin-treated plots, resistance frequency to difenoconazole was lower $(P<0.05)$ than that in control plots because only 5 to $6.6 \%$ of the isolates obtained from trifloxystrobin-treated and 6.6 to $8.3 \%$ of the isolates obtained from the pyraclostrobin-treated plots were resis- tant to difenoconazole (Fig. 1). In benomyl-treated plots, resistance frequency to difenoconazole had a value of $8.3 \%$ in 2003, which was lower $(P<0.05)$ than that in control plots; whereas, during 2004, it had a value of $10 \%$, which was similar $(P$ $>0.05$ ) to that in control plots (Fig. 1).

Benomyl applications selected for high resistance frequency to benomyl, because benzimidazole-resistant phenotypes reached levels of 68.3 and $75 \%$ in 2003 and 2004, respectively (Fig. 2). In contrast, resistance frequency to benomyl in plots treated with the strobilurin fungicides or with difenoconazole remained similar $(P>0.05)$ to that in the untreated control plots or was slightly lower, with values of 13.3 and $10 \%$ in trifloxystrobin plots, 10 and $11.6 \%$ in pyraclostrobin plots, and 11.6 and $10 \%$

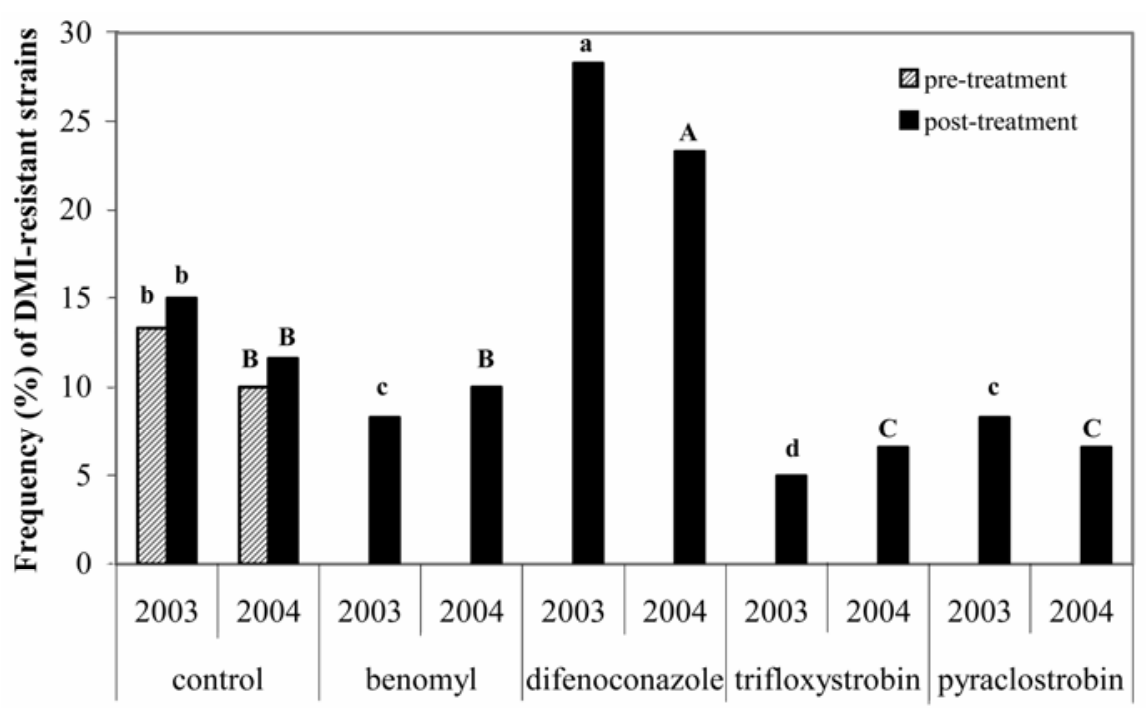

Fig. 1. Frequency of sterol demethylation-inhibiting (DMI)-resistant strains of Cercospora beticola in experimental field plots treated with various fungicides. Different letters on the columns indicate significantly differences according to Duncan multiple range test at $P=0.05$. Percentage values were transformed to arcsine $\sqrt{ } \%$ prior the statistical analysis.

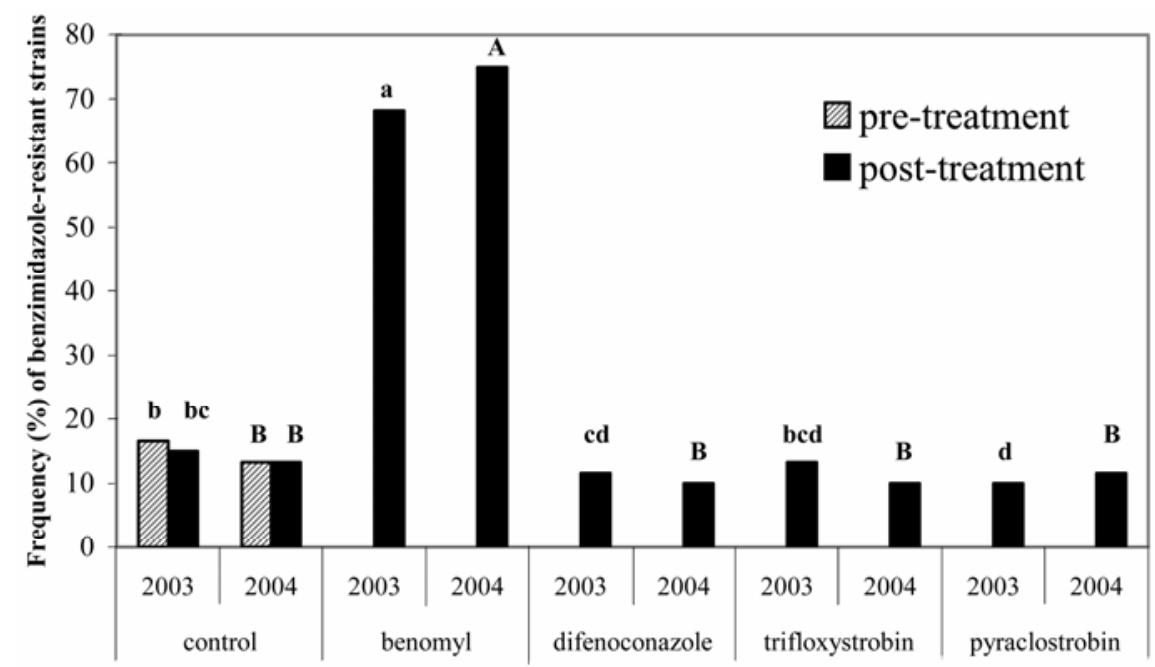

Fig. 2. Frequency of benzimidazole-resistant strains of Cercospora beticola in experimental field plots treated with various fungicides. Different letters on the columns indicate significantly differences according to Duncan multiple range test at $P=0.05$. Percentage values were transformed to arcsine $\sqrt{ } \%$ prior the statistical analysis.

in difenoconazole-treated plots during 2003 and 2004, respectively (Fig. 2). These slightly lower values of benzimidazole resistance frequency in strobilurinand difenoconazole-treated plots were statistically significant $(P<0.05)$ only in plots treated with pyraclostrobin during 2003.

\section{DISCUSSION}

Emergence of resistance to benzimidazole and DMI fungicides has become a limitation to the sustained control of Cercospora leaf spot of sugar beet. The development of new fungicide compounds with good efficacy against the disease and novel biochemical mechanisms of action and their introduction into the spray programs applied against Cercospora leaf spot is a prerequisite for successful disease management, particularly in areas with high disease pressure where problems of resistance to site-specific fungicides have emerged.

The results of this study showed that trifloxystrobin and pyraclostrobin can successfully control DMI- and benzimidazoleresistant strains of $C$. beticola. Under controlled environmental conditions, applications of both trifloxystrobin and pyraclostrobin, even at the very low concentration of $5 \mu \mathrm{g} \mathrm{ml}^{-1}$, provided satisfactory control of the disease on plants inoculated with either the BENR or DMIR isolate of the pathogen. At the same time, difenoconazole and benomyl applied at $10 \mu \mathrm{g} \mathrm{ml}^{-1}$ failed to protect satisfactorily plants inoculated with the DMIR and the BENR isolates, respectively. Additionally, excellent control of DMI- and benzimidazoleresistant strains of the pathogen was obtained by applications of trifloxystrobin and pyraclostrobin in mixtures with either difenoconazole or benomyl. Although the cross-resistance relationships among the strobilurin fungicides tested and difenoconazole or benomyl have not been tested in the current study, it can be assumed that there is no cross-resistance relationship among these fungicide classes because they possesses absolutely different modes of action $(10,22)$. The absence of crossresistance relationships among strobilurin and DMI fungicides has been observed in several other pathogens $(6,26,27,29)$ whereas, to the best of our knowledge, there is no published report related to the cross-resistance relationships between benzimidazole and strobilurin fungicides. However, it should be mentioned that there is a recent report related to a partial crosssensitivity between strobilurin and DMI fungicides in Uncinula necator (43). Based on this report, it could be assumed that resistance development to one fungicide class also accelerates resistance development to another unrelated fungicide class, as has been reported already in Venturia inaequalis among dodine and DMI fungicides $(24,25)$. These contradictory results 
suggest that a variation in the crossresistance relationships between strobilurin and DMI fungicides is likely to exist, depending on the fungal species or the different fungicides tested.

The conclusions derived from the in planta experiments were validated in a 2year field experiment. Both trifloxystrobin and pyraclostrobin provided excellent control of the disease in the experimental fields, despite the relatively high frequencies of DMI and benzimidazole resistance. In contrast, applications of benomyl provided ineffective control of the disease, whereas applications of difenoconazole, although more effective than those of benomyl, provided unsatisfactory control efficacy of the disease compared with the strobilurin fungicides tested.

Obviously, both pyraclostrobin and trifloxystrobin contributed to the control of DMI- and benzimidazole-resistant strains of the pathogen. The results of this experiment showed that the frequencies of DMI-resistant strains of the pathogen were decreased in plots treated with strobilurin fungicides compared with the untreated control plots, while the frequency of benzimidazole-resistant strains decreased in pyraclostrobin-treated plots during the first year of the study compared with the untreated control plots. In plots treated with either difenoconazole or carbendazim, the frequencies of DMI-resistant strains or benzimidazole-resistant strains, respectively, were higher compared with those from the untreated control plots. Thus, even within a single season, applications of DMI and benzimidazole fungicides tend to select for resistant phenotypes, as has been reported previously in $C$. beticola $(17,20)$ and in other pathogens $(7,8,37)$. Similarly, effective control was obtained by strobilurin fungicide applications against apple scab caused by $V$. inaequalis in a fully DMI-resistant orchard (23) and against DMI-resistant populations of Mycosphaerella fijiensis in banana (32), which is a fungal species closely related to $C$. beticola. Alternations between DMI and strobilurin fungicides in order to improve control and to counteract problems of resistance to DMI fungicides have been suggested in several pathosystems $(14,28$, $33,43,44)$.

Such results suggest that strobilurin fungicides could play a key role in Cercospora leaf spot management in the near future and encourage their introduction into the spray programs. However, it should be mentioned that their highly specific mode of action indicates a high risk for rapid selection of resistant genotypes among pathogen populations. Field resistance has developed in several pathogens, more rapidly than expected $(13,23,27$, $36,39)$. This potentially high risk for resistance development suggests the use of strategies in order to reduce this high risk according to guidelines issued by FRAC
(4). These guidelines include use of strobilurin fungicides in a limited number of applications, alternation with effective compounds from different cross-resistance groups, and use of mixtures with effective partner fungicides. Consequently, further research is required to design the most effective fungicide spray schedules and to select the most effective partners for use in mixtures. In addition, establishment of baseline sensitivities of $C$. beticola populations to the strobilurin fungicides in areas of high disease incidence requiring many fungicide spray applications for control of the disease would help in the development of resistance management strategies to this promising fungicide class.

\section{ACKNOWLEDGMENTS}

We thank BASF Hellas S.A. and Bayer Hellas S.A for providing the commercial formulations of pyraclostrobin and trifloxystrobin, respectively, that were not yet available in the Greek market; and S. Daucopoulos, E. Giannopoulos, and G. Akrivos for maintaining the field experiments.

\section{LITERATURE CITED}

1. Ammermann, E., Lorenz, G., Schelberger, K., Wenderoth, B., Sauter, H., and Rentzea, C. 1992. BAS $490 \mathrm{~F}-\mathrm{a}$ broad spectrum fungicide with a new mode of action. Pages 403-410 in: Proc. BCPC Conf.-Pests and Diseases. BCPC, Farnham, Surrey, UK.

2. Anesiadis, T., Karaoglanidis, G. S., and Tzavella-Klonari, K. 2003. Protective, curative and eradicant activity of the strobilurin fungicide azoxystrobin against Cercospora beticola and Erysiphe betae. J. Phytopathol. 151:647-651.

3. Anke, T. 1995. The antifungal strobilurins and their possible ecological role. Can. J. Bot. 73 (Suppl. 1):940-945.

4. Bartlett, D.W., Clough, J. M., Godwin, J. R., Hall, A. A., Hamer, M., and Parr-Dobrzanski, B. 2002. The strobilurin fungicides. Pest Manage. Sci. 58:649-662.

5. Byford, W. J. 1996. A survey of foliar diseases of sugar beet and their control in Europe. Pages 1-10 in: Proc. 59th IIRB Congr.

6. Chin, K. M., Küng-Färber, R., and Laird, D. 2000. Aspects of fungicide cross-resistance and implications for strobilurins. Pages 415420 in: Proc. BCPC Conf.-Pests and Diseases. BCPC, Farnham, Surrey, UK.

7. Cooke, L. R, Locke, T., Lockley, K. D., Phillips, A. N., Sadiq, M. D. S., Coll, R., Black, L, Taggart, P. J., and Mercer, P. C. 2004. The effect of fungicide programmes based on epoxiconazole on the control and DMI sensitivity of Rhyncosporium secalis in winter barley. Crop Prot. 23:393-406

8. Culbreath, A. K., Stevenson, K. L., and Brenneman, T. B. 2002. Management of late leaf spot of peanut with benomyl and chlorothalonil: A study in preserving fungicide utility. Plant Dis. 86:349-355.

9. D’Ambra, V., Mutto, S., and Carula, G., 1974. Sensibilita e toleranza di isolati di Cercospora beticola sensibili e toleranti al benomyl. Ind. Sacc. Ital. 1:11-13.

10. Delp, C. J. 1995. Benzimidazole and related fungicides, Pages 191-303 in: Modern Selective Fungicides-Properties, Applications, Mechanisms of Action. H. Lyr, ed. Gustav Fischer-Verlag, Jena, Germany.

11. Georgopoulos, S. G., and Dovas, C. 1973. Occurrence of Cercospora beticola strains resistant to benzimidazole fungicides in northern Greece. Plant Dis. Rep. 57:321-324.

12. Horsfall, J. G., and Barrat, R. W. 1945. An improved grading system for measuring plant diseases. (Abstr.) Phytopathology 35:655.

13. Ishii, H., Fraaije, B. A., Sugiyama, T., Nogouchi, K., Nishimura, K., Takeda, T., Amano, T., and Hollomon, D. W. 2001. Occurrence and molecular characterization of strobilurin resistance in cucumber powdery and downy mildew. Phytopathology 91:1166-1171.

14. Jayasena, K. W., Loughman, R., and Majewski, J. 2002. Evaluation of fungicides in control of spot-type net blotch on barley. Crop Prot. 21:63-69.

15. Karadimos, D. A., Karaoglanidis, G. S., and Tzavella-Klonari, K. 2005. Biological activity and physical modes of action of the $\mathrm{Q}_{0}$ inhibitor fungicides trifloxystrobin and pyraclostrobin against Cercospora beticola. Crop Prot. 24:23-29.

16. Karaoglanidis, G. S., Ioannidis, P. M., and Thanassoulopoulos, C. C. 2000. Reduced sensitivity of Cercospora beticola isolates to sterol demethylation inhibiting fungicides. Plant Pathol. 49:567-572.

17. Karaoglanidis, G. S., Ioannidis, P. M., and Thanassoulopoulos, C. C. 2001. Influence of fungicide spray schedules on the sensitivity to the sterol demethylation-inhibiting fungicides in Cercospora beticola. Crop Prot. 20:941947.

18. Karaoglanidis, G. S., Ioannidis, P. M., and Thanassoulopoulos, C. C. 2002. Changes in sensitivity of Cercospora beticola populations to sterol-demethylation-inhibiting fungicides during a 4-year period in northern Greece. Plant Pathol. 51:55-62.

19. Karaoglanidis, G. S., Karadimos, D. A., and Ioannidis, P. M. 2003. Detection of resistance to sterol demethylation-inhibiting fungicides (DMIs) in Cercospora beticola isolates and control efficacy of resistant and sensitive isolates with flutriafol. Phytoparasitica 31:373380.

20. Karaoglanidis,' G. S., Karadimos, D. A., Ioannidis, P. M., and Ioannidis, P. I. 2003. Sensitivity of Cercospora beticola populations to fentin-acetate, benomyl and flutriafol in Greece. Crop Prot. 22:735-740.

21. Khan, M. F. R., and Smith, L. R. 2005. Evaluating fungicides for controlling Cercospora leaf spot on sugar beet. Crop Prot. 24:79-86.

22. Köller, W. 1988. Sterol demethylation inhibitors: Mechanism of action and resistance. Pages 79-88 in: Fungicide Resistance in North America. C. J. Delp, ed. The American Phytopathological Society, St. Paul, MN.

23. Köller, W., Parker, D. M., Turechek, W. W., Avila-Adame, C., and Cronshaw, K. 2004. A two-phase resistance response of Venturia inaequalis to the $\mathrm{Q}_{0} \mathrm{I}$ fungicides kresoximmethyl and trifloxystrobin. Plant Dis. 88:537544.

24. Köller, W., and Wilcox, W. F. 2000. Interactive effects of dodine and the DMI fungicide fenarimol in the control of apple scab. Plant Dis. $84: 863-870$.

25. Köller, W., and Wilcox, W. F. 2001. Evidence for the predisposition of fungicide-resistant isolates of Venturia inaequalis to a preferential selection for resistance to other fungicides. Phytopathology 91:776-781.

26. Küng-Färber, R. B., Chin, K. M., and Leadbitter, N. 2002. Sensitivity of Venturia inaequalis to trifloxystrobin. Pest Manage. Sci. 58:261267.

27. Ma, Z., Felts, D., and Michailides, T. J. 2003. Resistance to azoxystrobin in Alternaria isolates from pistachio in California. Pestic. Biochem. Physiol. 77:66-74.

28. Margot, P., Huggenberger, F., Amrein, J., and Weiss, B. 1998. CGA 279202: A new broad spectrum strobilurin fungicide. Pages 375-382 in: Proc. BCPC Conf.-Pests and Diseases. BCPC, Farnham, Surrey, UK

29. Mavroeidi, V. I., and Shaw, M. W. 2005. Sensitivity distributions and cross-resistance pat- 
terns of Mycosphaerella graminicola to fluquinconazole, prochloraz and azoxystrobin over a period of 9 years. Crop Prot. 24:259266.

30. Meriggi, P., Rosso, F., Ioannides, P. M., and Ayala Garcia, J. 2000. Fungicide treatments against Cercospora leaf spot in sugar beet (Beta vulgaris L.). Adv. Sugar Beet Res. IIRB 2:77-102.

31. Pal, V., and Mukhopadhyay, A. N. 1985. Occurrence of strains of Cercospora beticola resistant to carbendazim (MBC) in India. Ind. J. Mycol. Plant Pathol. 13:333-334.

32. Perez, L., Hernandez, A., Hernandez, L., and Perez, M. 2002. Effect of trifloxystrobin and azoxystrobin on the control of black Sigatoka (Mycosphaerella fijiensis Morelet) on banana and plantain. Crop Prot. 21:17-23.

33. Reuveni, M. 2000. Efficacy of trifloxystrobin (Flint), a new strobilurin fungicide, in controlling powdery mildews on apple, mango and nectarine, and rust on prune trees. Crop Prot. 19:335-341.
34. Ruppel, E. G., and Scott, P. R. 1974. Strains of Cercospora beticola resistant to benomyl in the USA. Plant Dis. Rep. 58:434-436.

35. Shane, W. W., and Teng, P. S. 1992. Impact of Cercospora leaf spot on root weight, sugar yield and purity of Beta vulgaris. Plant Dis. 76:812-820.

36. Sierotzki, H., Wullschleger, J., and Gisi, U. 2000. Point mutation in cytochrome $b$ gene conferring resistance to strobilurin fungicides in Erysiphe gramminis f. sp. tritici field isolates. Pestic. Biochem. Physiol. 68:107-112.

37. Smith, C. M. 1988. History of benzimidazole use and resistance. Pages 23-24 in: Fungicide Resistance in North America. C. J. Delp, ed. The American Phytopathological Society, St. Paul, MN.

38. Tuite, J. 1969. Plant Pathological Methods. Burgess Publishing Company, Minneapolis, $\mathrm{MN}$.

39. Vincelli, P., and Dixon, E. 2002. Resistance to $\mathrm{Q}_{\mathrm{o}} \mathrm{I}$ (strobilurin like) fungicides in isolates of Pyricularia grisea from perennial ryegrass.
Plant Dis. 86:235-240.

40. Weiland, J. J., and Halloin, J. M. 2001. Benzimidazole resistance in Cercospora beticola sampled from sugar beet fields in Michigan, USA. Can. J. Plant Pathol. 23:78-82.

41. Wolf, P. F. J., and Verreet, J. A. 2002. The IPM sugar beet model-An integrated pest management system in Germany for the control of fungal leaf diseases in sugar beet. Plant Dis. 86:336-344.

42. Wong, F. P., and Wilcox, W. F. 2001. Comparative physical modes of action of azoxystrobin, mancozeb and metalaxyl against Plasmopara viticola. Plant Dis. 85:649-656.

43. Wong, F. P., and Wilcox, W. F. 2002. Sensitivity to azoxystrobin among isolates of Uncinula necator: Baseline distribution and relationship to myclobutanil sensitivity. Plant Dis. 86:394404.

44. Ypema, H. L., and Gold, R. E. 1999. Kresoxim-methyl: Modification of a naturally occurring compound to produce a new fungicide. Plant Dis. 83:4-19. 